\title{
Relationship between Static Lower Limb Alignment and Patellofemoral Pain Syndrome
}

\author{
GAMILA S.T. ABBAS, M.Sc.*; NADIA A. FAYAZ, Ph.D.**; KARIMA A. HASSAN, Ph.D.** and \\ AHMED H. ABD EL-AZEEM, M.D.***
}

The Orthopedic Outpatient Clinic, Physical Therapy Unit, Kasr El-Aini Hospital*, The Department of Musculoskeletal Disorders, Faculty of Physical Therapy, Cairo University** and The Department of Orthopedic Surgery, Faculty of Medicine, Cairo University***, Egypt

\begin{abstract}
Background: Patellofemoral Pain Syndrome (PFPS) is one of the most common orthopedic knee conditions encountered in athletes and general population and is more prevalent in females than in males. Lower limb malalignment is an important etiological factor for PFPS.
\end{abstract}

Aim of the Study: The purpose of this study was to determine if there was any relationship between static lower extremity alignment and PFPS.

Patients and Methods: Forty nine patients (38 females and 11 males) diagnosed as PFPS had participated in this study with age ranged from eighteen to thirty five years. Each patient was assessed for static lower limb alignment measures (pelvic tilting angle, tibial torsion using PALM (PALpation meter); femoral neck anteversion using inclinometer; Q-angle, tibiofemoral angle using plastic standard goniometer and navicular drop using ruler) and patellofemoral pain by kujala scale.

Results: The results showed no relationship between lower limb alignment measures and PFPS Pelvic angle $(\rho=0.03$, $p=0.839)$, Tibial torsion $(\rho=0.145, p=0.319)$, Q-angle $(\rho=$ $0.074, p=0.612)$, Tibiofemoral angle $(\rho=0.051, p=0.729)$, FNA $(\rho=0.144, p=0.436)$, Navicular drop $(\rho=0.03, p=0.836)$.

Conclusion: Lower extremity malalignment does not affect pain and function in patients with PFPS.

Key Words: Patellofemoral pain syndrome - Static lower extremity alignment.

\section{Introduction}

PATELLOFEMORAL Pain Syndrome (PFPS) is one of the most common knee joint dysfunctions among young physically active individual [1]. It accounts for $10 \%$ to $25 \%$ of all visits seen in physical therapy clinics [2]. The prevalence of PFPS is 1.5 times higher in females than males [3]

Correspondence to: Dr. Gamila S.T. Abbas, The Orthopedic Outpatient Clinic, Physical Therapy Unit, Kasr El-Aini Hospital, Egypt
Despite the high incidence of PFPS, the pathomechanics of this disorder remain poorly understood [4]. Some theories for the origin of non traumatic gradual onset of PFPS are: (1) Neuromuscular imbalance of the Vastusmedialis Obliqus (VMO) and the Vastuslateralis (VL) muscles; [5] (2) Tightness of the lateral knee retinaculum, hamstrings, iliotibial band, and gastrocnemius; [6] (3) Over pronation of the subtalar joint [7] and (4) Hip muscles weakness have been suspected to increase patellofemoral malalignment and the advancement of PFPS signs and symptoms [4].

Previous literatures suggested that, in the absence of direct trauma, the etiology of PFPS is multi factorial. Factors related directly to the Patellofemoral Joint (PFJ) [8], factors distal to the knee [9], and proximal factors including hip muscles weakness have also been proposed to contribute to patellofemoral malalignment and the development of PFPS [10].

Lower Extremity Alignment (LEA) has been proposed as a risk factor for acute and chronic lower extremity injuries, including PFPS [11] and anterior cruciate ligament injuries [12]. Skeletal malalignment can alter the joint load distribution and, therefore, joint contact pressure distribution of adjacent or distant joints [13]

It is important to recognize and quantitate lower limb alignment in the diagnosis and treatment of PFJ symptoms and disorders. To researcher's knowledge few published studies have addressed the relationship among LEA and function in PFPS patients, this relationship may be important because one skeletal malalignment may cause compensatory alignment changes at other bony segments, resulting 
in abnormal stress patterns or compensatory motions along the kinetic chain.

Static alignment measurements of leg length discrepancy, Femoral Neck Anteversion (FNA), knee genu varum, valgum and recurvatum, excessive Q-angle (greater than 20 degrees) [14], patella alta, tibial torsion, increased ankle dorsi flexion, and excessive subtalar and forefoot varus (navicular drop more than $15 \mathrm{~mm}$ ) [15] have been proposed as potential intrinsic risk factors for running injury [16].

\section{Patients and Methods}

Upon approval of Cairo University's supreme council of postgraduate studies and research, the study extended from January 2017 to June 2017. Forty nine patients (38 females and 11 males) referred from orthopedic surgeon diagnosed as PFPS. Their mean age, body mass, height, BMI values were $24.94 \pm 3.69$ years, $67.4 \pm 11.41 \mathrm{Kg}$, $164.24 \pm 8.26 \mathrm{~cm}$, and $23.32 \pm 3.71 \mathrm{Kg} / \mathrm{m}^{2}$ respectively. They were interviewed and screened based on the following inclusion criteria: Anterior or retropatellar knee pain from at least 2 of the following activities: Prolonged sitting; stair climbing; squatting; running; kneeling; and hopping/jumping [17], non-traumatic incident ( 6 months to 1 year), their age ranged from 18-35 years and BMI under 30 . The exclusion criteria were: A history of any of the following conditions: Meniscal or other intra articular pathologic conditions; cruciate or collateral ligament involvement, a history of traumatic patellar subluxation or dislocation, previous surgery in the knee, ankle and hip joints, knee, ankle and hip joints osteoarthritis. This study was conducted at Kasr El-Aini Outpatient Clinic, Cairo, Egypt.

\section{Procedures:}

Each subject was assessed for six static lower extremity alignment for both limbs: (Pelvic tilting angle and tibial torsion using the PALM, FNA by bubble inclinometer, Q-angle and tibiofemoral angle using goniometer, navicular drop by a ruler) and pain assessment by kujala questionnaire (Appendix).

\section{1- Anterior pelvic tilting angle:}

Pelvic angle was measured in bilateral stance while the subject standing and bearing equal weight on both lower limbs Fig. (1). This angle represents the angle formed by a line from the ASIS to the PSIS relative to the horizontal plane using inclinometer. This method with measurements done using inclinometer has been reported to have an ICC of 0.77 to 0.99 for intratester reliability [18].
Pelvic angle measures were taken in a standardized stance, with left and right feet spaced equal to the width of the left and right acromial processes and toes facing forward. The stance was achieved by instructing participants to march in place and then took a step forward. They were instructed to look straight ahead during standing measures with equal weight over both feet [19]

\section{2- Femoral neck anteversion:}

The bubble inclinometer was calibrated by zeroing it to a fixed vertical reference using the wall. The participant lied in prone with the knee flexed to $90^{\circ}$ and the pelvis is fixed to the plinth using a belt Fig. (2), the examiner passively rotated the hip joint internally until a firm end point was reached then passively rotated the hip joint externally, the hip angle was measured by placing the bubble inclinometer over the distal third of the tibia and the degree difference between them was recorded [20]

\section{3-Q-angle:}

Q-angle Fig. (3) was measured from a standing position as the angle between a line passing from ASIS to the center of the patella and another line from the patellar center to the tibial tuberosity using the universal goniometer. As the quadriceps contraction may affect the position of the patella, special care was taken to ensure that the participant's quadriceps muscle was relaxed [21]. This was done by giving clear instructions to the subject and teaching him how to relax the muscle, and was confirmed by palpation.

\section{4- Tibiofemoral angle:}

Tibiofemoral angle Fig. (4) was measured from standing. With the goniometer axis over the patellar center, the angle was measured by a line from the knee center to a mid way landmark between the ASIS and the greater trochanter, and a line from the knee center to the mid-malleolar distance [22]

\section{5- Tibial torsion:}

The participant was positioned in supine lying position Fig. (5), the examiner passively positioned the femur so that the line between the epicondyles is parallel to the horizontal plane. Tibial torsion was measured as the angle between the true horizontal and the bi-malleolar axis. This angle was measured using PALM inclinometer by placing the two caliper arms on the medial and lateral malleolus and recording the angle displayed by the inclinometer. Normal tibial torsion was reported to be on average $25^{\circ}$ in adult population [23] 


\section{6- Navicular drop test:}

Navicular drop Fig. (6) was determined as the difference in height of the navicular tuberosity from the floor during sitting and standing. An initial measurement was taken with the participant seated, both feet on the floor, un-weighted, and in subtalar neutral. The unweighted navicular position is the distance from the floor to the marked point on the navicular tuberosity. The participant then was asked to stand and was instructed to keep equal pressure on both feet while the measurement was repeated. Navicular drop was calculated as the difference between the two measurements [18]

\section{Functional assessment:}

All patients were assessed for their functional status by completing Kujala questionnaire for patellofemoral joint pain (anterior knee pain scale) that has been validated for the evaluation of patellofemoral joint disorders. The maximum total score

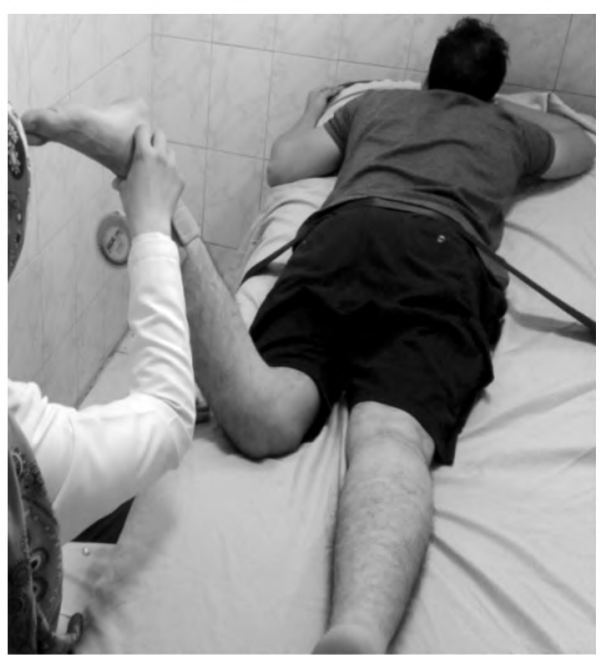

of this assessment tool was 100 , with higher scores indicating greater levels of function with lower levels of pain (Appendix).

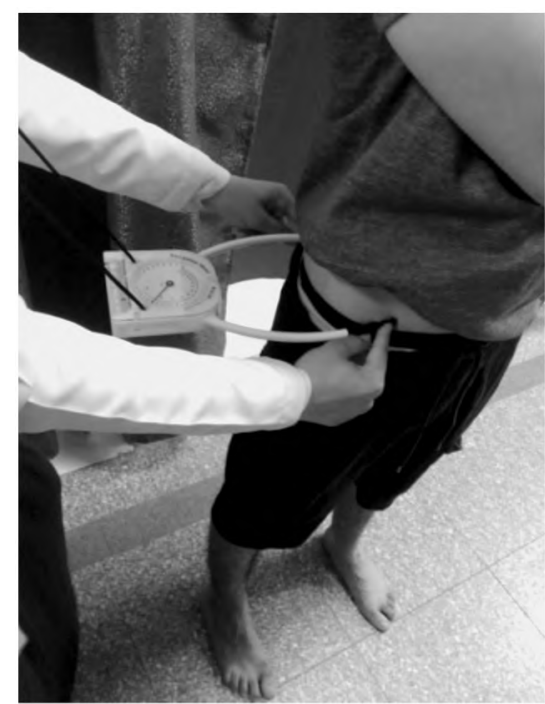

Fig. (1): Pelvic angle measurement.

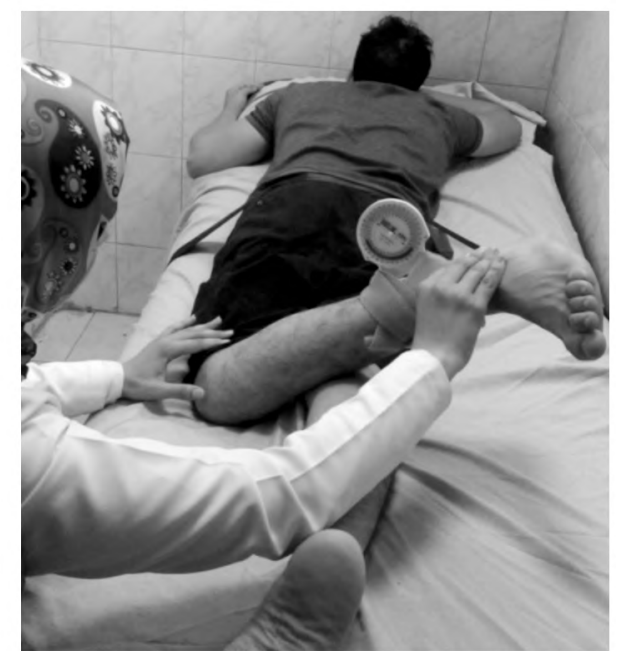

Fig. (2): Femoral neck anteversion angle measurement. Right: External rotation. Left: Internal rotation.

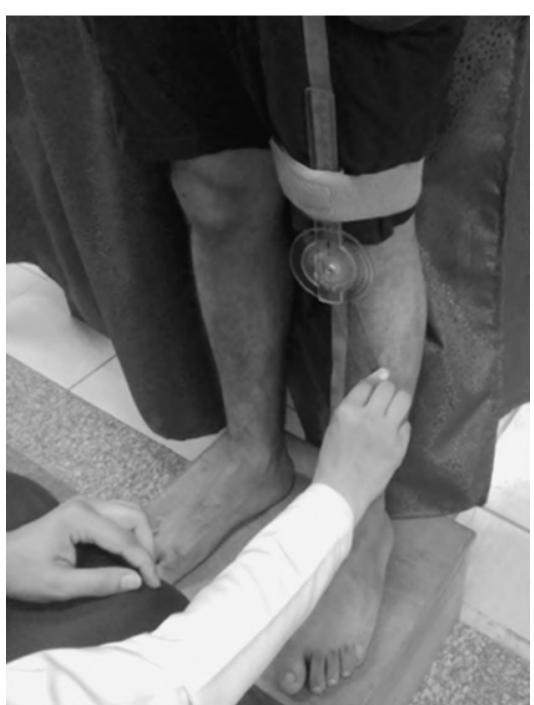

Fig. (3): Q-angle measurement.

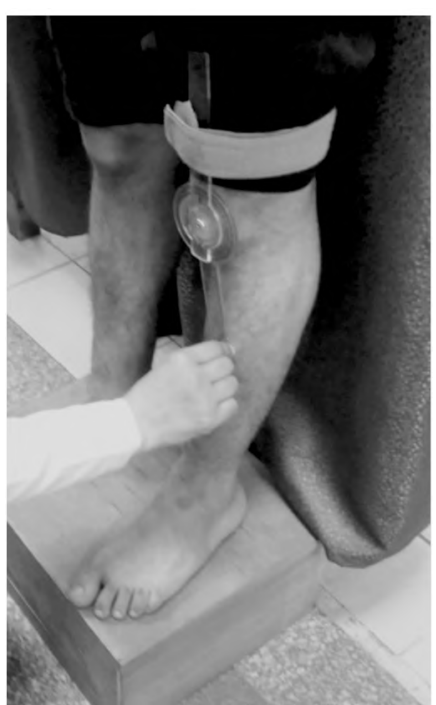

Fig. (4): Tibiofemoral angle measurement. 


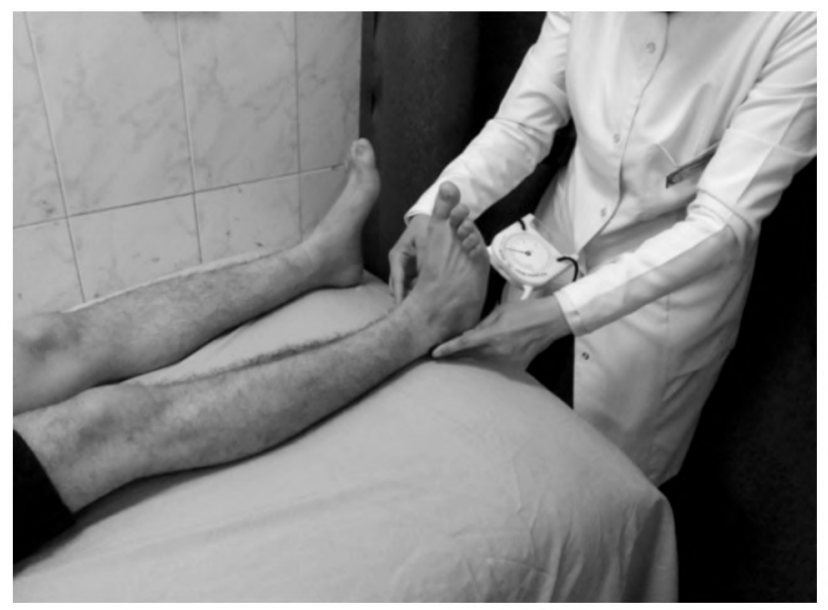

Fig. (5): Tibial torsion measurement.
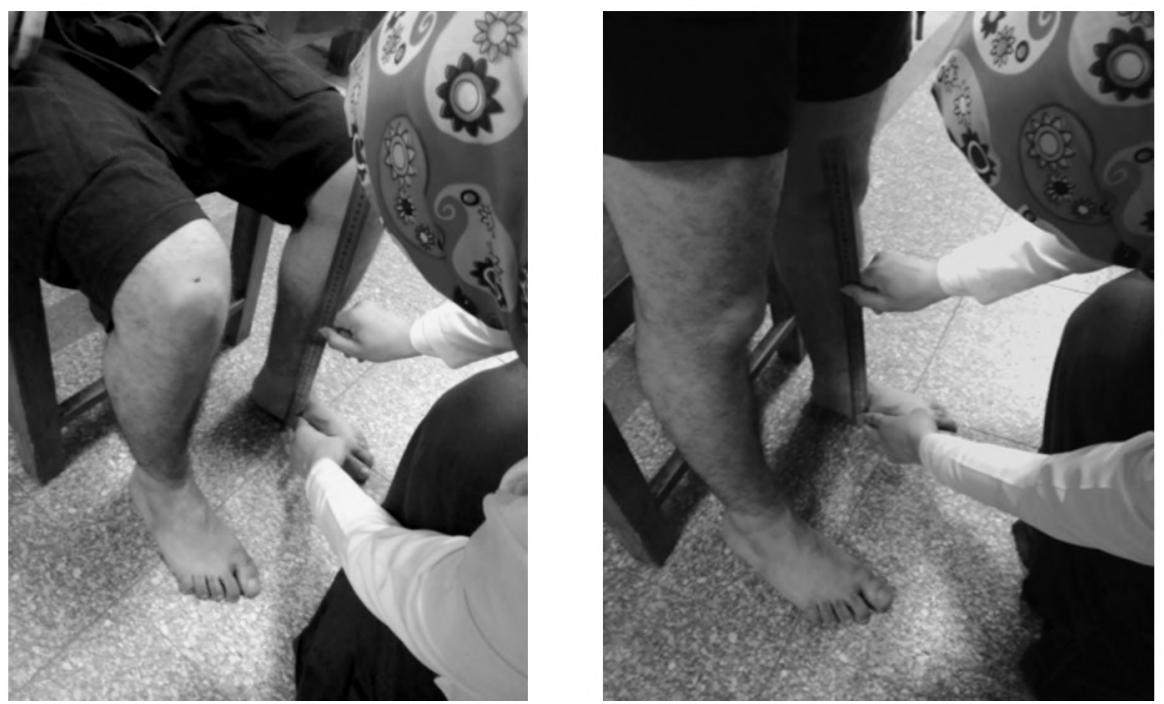

Fig. (6): Navicular drop test. (Left): The distance of the navicular tuberosity from the floor was measured from sitting. (Right): The same distance was measured again from standing.

\section{Results}

Statistical analysis was conducted using SPSS for windows, Version 22 (SPSS, Inc., Chicago, IL). Prior to final analysis, data were screened for normality assumption and presence of extreme scores. This exploration was done as a pre-requisite for parametric calculations of the analysis of difference. Descriptive analysis using histograms with the normal distribution curve showed that the AKPS, pelvic angle, tibial torsion, FNA, Q-angle, TFA, and navicular drop were not normally distributed and violates the parametric assumption for the measured dependent variable. Normality test of data using Shapiro-Wilk test was used, that reflect the data was not normally distributed for all most dependent variables. Spearman product moment correlation coefficient was used to determine the correlations among the AKPS, pelvic angle, tibial torsion, FNA, Q-angle, TFA, and navicular drop. The initial alpha level for the correlation analysis was set at 0.05 .

\section{General characteristics:}

The current study was conducted on 49 participants (38 females and 11 males) suffering from PFPS their mean age, body mass, height, BMI values were $24.94 \pm 3.69$ years, $67.4 \pm 11.41 \mathrm{Kg}$, $164.24 \pm 8.26 \mathrm{~cm}$, and $23.32 \pm 3.71 \mathrm{Kg} / \mathrm{m}^{2}$ respectively.

Correlation among the AKPS, pelvic angle, tibial torsion, FNA, $Q$-angle, TFA, and navicular drop:

The correlations among the AKPS, pelvic angle, tibial torsion, FNA, Q-angle, TFA, and navicular drop were studied through the Spearman product moment correlation coefficient. It revealed that there was no correlation between AKPS and pelvic angle ( $\rho=0.03, p=0.839$ ). Additionally, there was no correlation between AKPS and tibial torsion $(\rho=0.145, p=0.319)$, between AKPS and FNA $(\rho=$ $-0.144, p=0.436$ ), as well as between AKPS and Q-angle $(\rho=0.074, p=0.612)$, moreover there was 
no correlation between AKPS and TFA ( $\mathrm{p}=0.051$, $p=0.729$ ). Finally, there was no correlation between

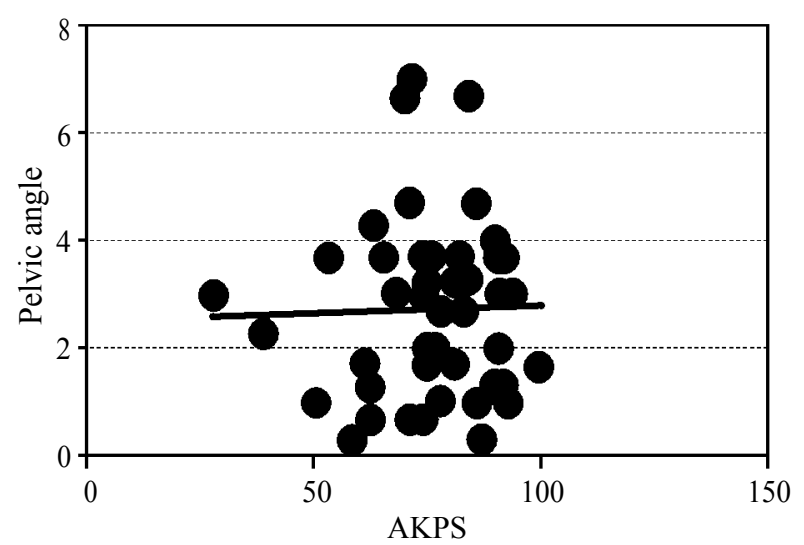

Fig. (7): Scatter plot for the bivariate correlation between AKPS and pelvic angle.

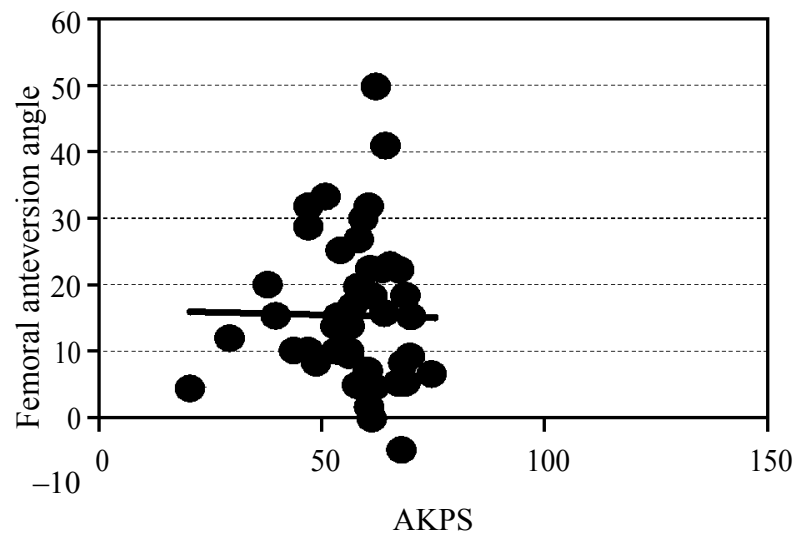

Fig. (9): Scatter plot for the bivariate correlation between AKPS and femoral anteversion angle.

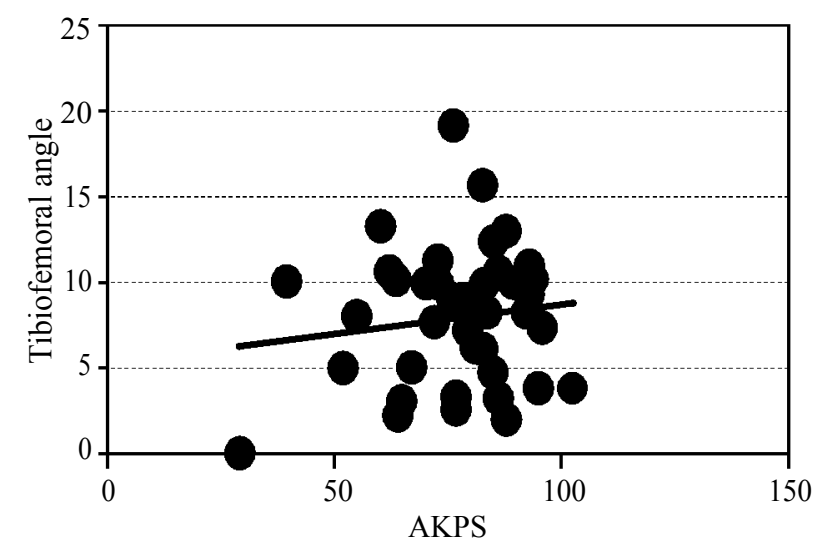

Fig. (11): Scatter plot for the bivariate correlation between AKPS and tibiofemoral angle.

\section{Discussion}

The main purpose of this study was to investigate the relationship between static Lower Extremity Alignment (LEA) and Patellofemoral Pain
AKPS and navicular drop ( $\mathrm{p}=0.03, p=0.836)$ (as shown in Figs. (7-12).

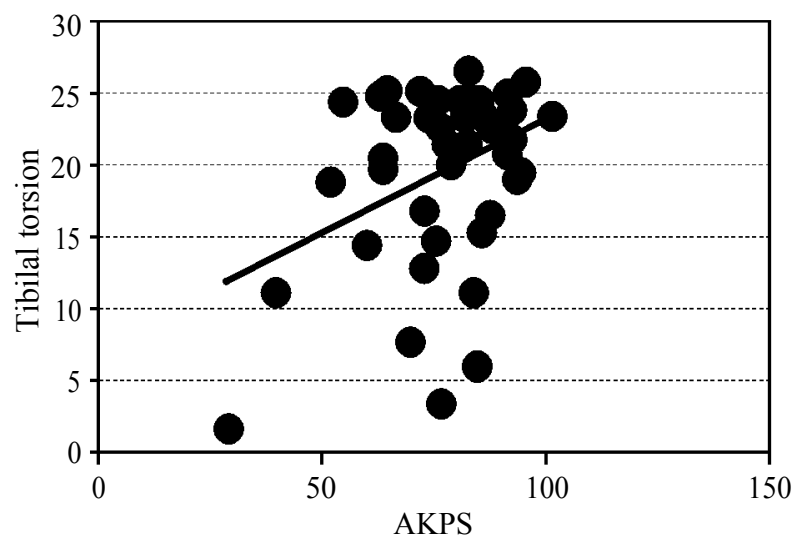

Fig. (8): Scatter plot for the bivariate correlation between AKPS and tibial torsion.

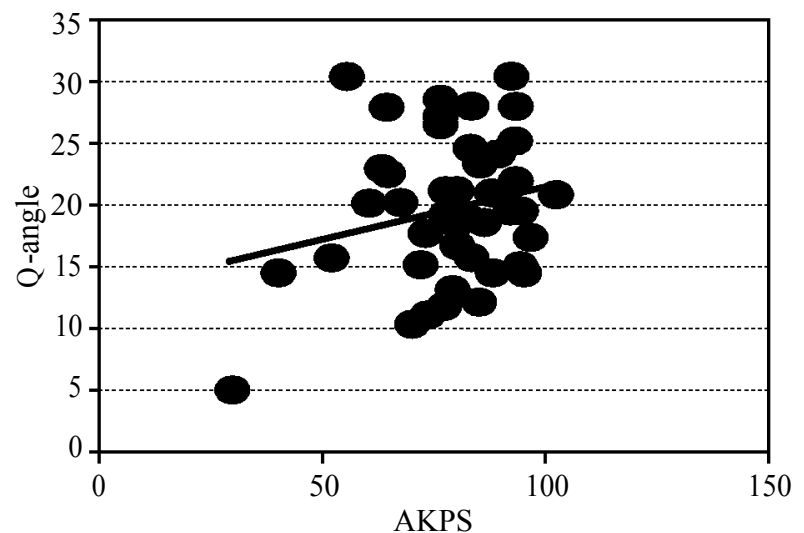

Fig. (10): Scatter plot for the bivariate correlation between AKPS and Q-angle.

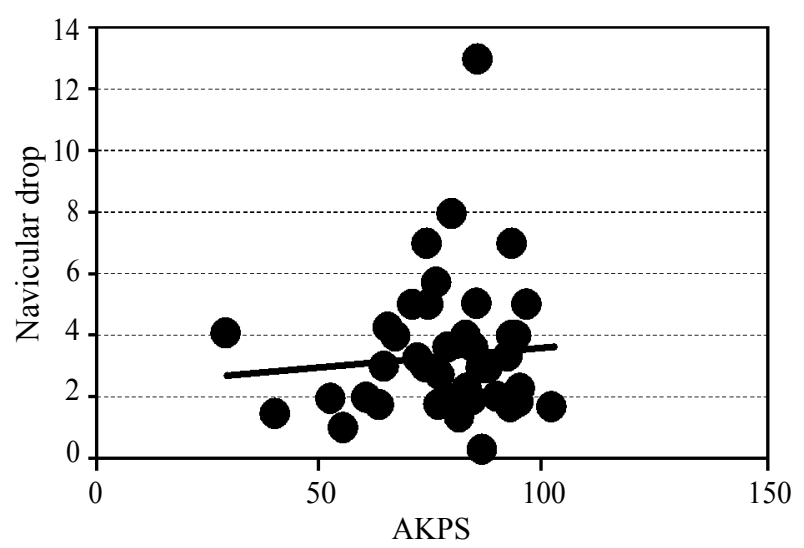

Fig. (12): Scatter plot for the bivariate correlation between AKPS and navicular drop.

Syndrome (PFPS). The study general hypothesis stated that there would be no relationship between static lower extremity alignment measures and PFPS. The results of this study accept this general hypothesis as there were no association between 
pelvic angle, tibial torsion, FNA, Q-angle, tibiofemoral angle, navicular drop and PFPS ( $\mathrm{p}$ less than 0.145 and $p=0.05$ ).

Nakagawa et al., [24] found that greater hip adduction, hip internal rotation, and knee abduction were associated with higher levels of pain and reduced function in males and females with PFP.

Therefore, the higher the number of kinematic alterations (pelvic angle, tibial torsion, FNA, Qangle, tibiofemoral angle, and navicular drop, the worse the symptoms and function, which have been shown to be associated with a poor prognosis [25]. Bakry et al., [26] found no relationship between static LEA measures (pelvic angle, tibial torsion, FNA, TFA, Q-angle, navicular drop) and hamstring strain injury in Egyptian soccer players.

\section{Relationship between pelvic angle and PFPS:}

It was hypothesized that there would be no relationship between pelvic angle and PFPS. Based on the results of present study, this hypothesis was accepted as evident by no relationship between pelvic angle and PFPS ( $\mathrm{p}=0.03, p=0.839)$. The lack of statistical significance could be attributed to the small sample size. Thus, further research with a larger sample size is warranted before conclusion on the relationship between pelvic angle asymmetry and PFPS.

Due to scarcity of literatures in this area, our results cannot be compared to other studies in PFPS. However, associations between pelvic angle asymmetry and other musculoskeletal dysfunctions exist. For example, one study reported association between increased foot pronation, decreased pelvic tilt angle and increased anterior knee laxity [27] .

Hertel et al., [28] found that increased anterior pelvic tilt was significantly associated with ACL injury history. This study support the work of Loudon et al., [29] who found that in females anterior pelvic tilt was significantly related to having a history of ACL injury when assessed statistically in a univariate analysis, however it was not a significant factor when examined in a multivariate analysis.

Based on clinical observations [30] and previous research [27] expectation was that greater anterior pelvic tilt would be related to greater anterior knee laxity concomitant to its proposed effect on alignment of the hip (femoral internal rotation), knee (valgus and genu recurvatum), and ankle (pronation).

\section{Relationship between Tibial torsion and PFPS:}

It was hypothesized that there would be no relationship between tibial torsion and PFPS. Based on the results of present study, this hypothesis was accepted as evident by no relationship between tibial torsion and PFPS $(\mathrm{p}=0.145, p=0.319)$.

Literature search failed to find previous studies that investigated the relationship between tibial torsion and PFPS. Similarly, Shultz et al., [27] concluded that tibial torsion is not a significant predictor for anterior knee laxity. However, it was proposed by Meyer and Haut [31] that excessive internal tibial torsion can increase the risk of developing ACL injury. Also Amis and Dawkins [32] found that internal tibial torsion was a predictor for ACL and Medial Collateral Ligament (MCL) injuries.

Guler et al., [33] concluded that torsional abnormalities were considered both a possible cause and effect of OA. Turner [34] suggested that patients with OA of the knee had reduced external torsion or true internal torsion. In addition, Yagi [35] reported that tibial torsional deformities occurred in association with medial type osteoarthritic knees.

\section{Relationship between femoral anteversion and PFPS:}

It was hypothesized that there would be no relationship between FNA and PFPS. Based on the results of present study, this hypothesis was accepted as evident by no relationship between FNA and PFPS ( $\rho=-0.144, p=0.436$ ). Findings of the present study agree with the work of Reikeras [36] who found no relationship between FNA and PFPS.

Findings of the present study disagree with the work of Montgomery et al., [37] who found a relationship between FNA and PFPS. Eckhoff [38] found a relationship between femoral anteversion, osteoarthritis of the knee and patellar instability. Increased anteversion had been associated with anterior knee laxity [27], ACL injury [39] .

\section{Relationship between Q-angle and PFPS:}

It was hypothesized that there would be no relationship between Q-angle and PFPS. The present study supported this hypothesis $(\mathrm{p}=0.074$, $p=0.612$ ). Almeida et al., [40] supported our study as they conducted a cross sectional study on females with PFPS and fonud that there was no significant correlation between Q-angle, pain intensity ( $r=$ $-0.29 ; p=0.19$ ), functional capacity ( $r=-0.08$; $p=0.72$ ). 
Furthermore, Thij s et al., and Ramskov et al., [41,42] prospectively monitored novice street runners and found that the Q-angle did not differ between the athletes who developed PFPS and those who did not. Thus, they did not consider it to be a risk factor. Similar findings were reported by Boling et al., [43] from a prospective study on 1319 participants, with three years of follow-up. Furthermore, a recent systematic review with metaanalysis confirmed the lack of relationship between an excessive Q-angle and development of PFPS. In addition to that, Witvrouw et al., [14] agree with the present study as they did not find any relationship between Q-angle and PFPS. Also, Lun et al., [44] agreed with our study as they measured static lower limb alignment in 87 recreational runners before their training period and observed their injury history over six months of their usual training program. They found no strong evidence that lower extremity alignment is associated with running injuries, including PFPS.

Findings of the present study disagree with the work of Emami et al., [45] who found a correlation between Q-angle and PFPS. The contrasting results between the current study and the previous study may be due to larger sample size. Excessive Qangle has been identifying as a risk factor for some musculoskeletal injuries for example, ACL injury [39] and overuse lower extremity injuries [46].

\section{Relationship between Tibiofemoral angle and PFPS:}

It was hypothesized that there would be no relationship between tibiofemoral angle and PFPS. Our study supported this hypothesis $(\mathrm{p}=0.051, p=$ 0.729 ). The findings of this study disagree with the work of Park and Stefanyshyn [47] who found that varus knee alignment was seen in $32 \%$ of PFPS patients. Decreased tibiofemoral angle has been associated with increased anterior knee laxity [27] and ACL injury [39].

\section{Relationship between foot pronation and PFPS:}

It was hypothesized that there would be no relationship between foot pronation and PFPS. Our study supported this hypothesis $(\rho=0.03, p=0.836)$. The present study agree with the work of Aliberti et al., [48] who conducted a study on 77 adults of both genders and found that there was no association between increased rearfoot valgus $(p=0.67)$ and PFPS occurrence.

This finding is in agreement with other studies, which found no difference between rearfoot posture in stance and the occurrence of PFPS [49]. On the other hand Barton et al., [50] found a relation between increased rearfoot valgus and increased calcaneal angle during relaxed stance posture in subjects with PFPS. The contrasting results between the current study and that of Barton et al., [50] may be due to methodological difference as he measured rear foot angle by digital photogrammetry.

Excessive rearfoot pronation has been linked to overuse injuries of the knee [51] such as ACL injuries [29]. Navicular drop has been proposed to be a strong predictor for other musculoskeletal dysfunctions such as anterior knee laxity [27] and was also significantly associated with ACL injury [39].

\section{Conclusion:}

Based on the scope and findings of this study, it could be concluded that there was no relationship between static LEA (pelvic angle, tibial torsion, FNA, Q-angle, TFA, navicular drop) and anterior knee pain in patients with PFPS. Static LEA does not related to functional ability in patients with PFPS.

\section{References}

1- LOPES A.D., JUNIOR L.C.H. and YEUNG S.S.: What are the main running related musculoskeletal injuries? A systematic review. Sports Med., 42: 891-905, 2012.

2- RATHLEFF M.S., RATHLEFF C.R. and OLESEN J.L.: Is knee pain during adolescence a self-limiting condition? Prognosis of patellofemoral pain and other types of knee pain. Am. J. Sports Med., 44 (5): 1165-71, 2016.

3- ROUSH J.R. and BAY R.C.: Prevalence of anterior knee pain in 18-35 year-old females. Int. J. Sports Phys. Ther., 7 (4): 396-401, 2012.

4- SOUZA R.B. and POWERS C.M.: Differences in hip kinematics, muscle strength, and muscle activation between subjects with and without patellofemoral pain syndrome. J. Orthop. Sports Phys. Ther., 39 (1): 12-9, 2009a.

5- COWAN S., HODGES P.W., BENNELL K. and CROSSLEY K.: Altered vastii recruitment when people with patellofemoral pain syndrome complete a postural task. Arch. Phys. Med. Rehabil., 83: 989-95, 2002.

6- PIVA S.R., GOODNITE E.A. and CHILDS J.D.: Strength around the hip and flexibility of soft tissues in individuals with and without patellofemoral pain syndrome. J. Orthop. Sports Phys. Ther., 35 (12): 793-801, 2005.

7- ZAPPALA F.G., TAFFEL C.B. and SCUDERI G.R. Rehabilitation of patellofemoral joint disorders. Orthop. Clin. North Am., 23: 555-66, 1992.

8- FREDERICSON M. and YOON K.: Physical examination and patellofemoral pain syndrome. Am. J. Phys. Med. and Rehabil., 85: 234-43, 2006.

9- VICENZINO B., COLLINS N., CROSSLEY, BELLER E., DARNELL R. and MCPOIL T.: Foot orthoses and physiotherapy in the treatment of patellofemoral pain 
syndrome: A randomized clinical trial. Musculoskeletal disorders, 9: 27, 2008.

10- JACOBSEN J.S., THORBORG K., SOBALLE K. and ULRICH-VINTHER M.: Eccentric hip abductor weakness in patients with symptomatic external snapping hip. Scand J. Med. Sci. Sports, 22 (6): 140-6, 2012.

11- POWERS C.M., CHEN P.Y., REISCHL S.F. and PERRY J.: Comparison of foot pronation and lower extremity rotation in persons with and without patellofemoral pain. Foot Ankle Int., 23: 634-40, 2002.

12- DANESHMANDI H. and SAKI F.: The study of static lower extremity posture in female athletes with ACL injuries. Sport Med., 1: 75-91, 2009.

13- RIEGGER-KRUGH C. and KEYSO J.J.: Skeletal malalignments of the lower quarter: Correlated and compensatory motions and postures. J. Orthop. Sports Phys. Ther., 23: 164-70, 1996.

14- WITVROUW E., LYSENS R., BELLEMANS J., CAMBIER D. and VANDERSTRAETEN G.: Intrinsic risk factors for the development of anterior knee pain in an athletic population. A two-year prospective study. Am. J. Sports Med., 28: 480-9, 2000.

15- McPOIL T.G., CORNWALL M.W., ABELER M.G., DEVEREAUX K.J., FLOOD L.J., MERRIMAN S.E., et al.: The optimal method to assess the vertical mobility of the midfoot: Navicular drop versus dorsal arch height difference? Clin. Res. Foot Ankle, 1 (1): 1-7, 2013.

16- RYAN M.B., MacLEAN C.L. and TAUNTON J.E.: A review of anthropometric, biomechanical, neuromuscular and training related factors associated with injury in runners. Int. Sport Med., 7 (2): 120-37, 2006.

17- TYLER T.F., NICHOLAS S.J., MULLANEY M.J. and MUCHUGH M.P.: The role of hip muscle function in the treatment of patellofemoral pain syndrome. Am. J. Sports Med., 34: 630-6, 2006.

18- SHULTZ S.J., CARCIA C.R., GANSNEDER B.M. and PERRIN D.H.: The independent and interactive effects of navicular drop and Quadriceps angle on neuromuscular responses to a weight-bearing perturbation. J. Athl. Train., 41 (3): 251-9, 2006.

19- NGUYEN A. and SHULTZ S.: Identifying relationships among lower extremity alignment characteristics. J. Athl. Train., 44 (5): 511-8, 2009.

20- VANDILLEN L.R., BLOOM N.J., GOMBATTO S.P. and SUSCO T.M.: Hip rotation range of motion in people with and without low back pain who participate in rotationrelated sports. Phys Ther in Sport: Official Journal of the Association of Chartered Physiotherapists in Sports Medicine, 9 (2): 72-81, 2008.

21- LIVINGSTON L.A. and MANDIGO J.L.: Bilateral Qangle asymmetry and anterior knee pain syndrome. Clin. Biomech. (Bristol, Avon), 14 (1): 7-13, 1999.

22- CHAO E.Y., NELUHENI E.V., HSU R.W. and PALEY D.: Biomechanics of malalignment. The Orthop. Clin. North Am., 25 (3): 379-86, 1994.

23- NGUYEN A.D. and SHULTZ S.J.: Sex differences in clinical measures of lower extremity alignment. J. Orthop. Sports Phys. Ther., 37: 389-98, 2007.
24- NAKAGAWA T.H., SERRÃO F.V., MACIEL C.D. and POWERS C.M.: Hip and knee kinematics are associated with pain and self-reported functional status in males and females with patellofemoral pain. Int. J. Sports Med., 34: 997-1002, 2013.

25- LANKHORST N.E., VAN MIDDELKOOP M., CROSSLEY K.M., BIERMA-ZEINSTRA S.M.A., OEI E.H.G. and VICENZINO B.: Factors that predict a poor outcome 5-8 years after the diagnosis of patellofemoral pain: A multicentre observational analysis. Br. J. Sports Med., 094664, 2015.

26- BAKRY M.G., REHAN YOUSSEF A. and SAWEERES E.S.: Clinical assessment of lower limb static alignment using the photogrammetric method (poster presentation). In 9th International Deformity Correction Conference. Mena House Oberoi Hotel, Cairo, Egypt, 2013.

27- SHULTZ S.J., NGUYEN A.D. and LEVINE B.J.: The relationship between lower extremity alignment characteristics and anterior knee joint laxity. Sports Health, 1(1): 54-60, 2009.

28- HERTEL J., DORFMAN J.H. and BRAHAM R.A.: Lower extremity malalignments and anterior cruciate ligament injury history. J. Sports Sci. Med., 3 (4): 220-5, 2004.

29- LOUDON J.K., JENKINS W. and LOUDON K.L.: The relationship between static posture and ACL injury in female athletes. J. Orthop. Sports Phys. Ther., 24 (2): 917, 1996.

30- HRUSKA R.: Pelvic stability influences lower extremity kinematics. J. Biomech., 6: 23-9, 1998.

31- MEYER E.G. and HAUT R.C.: Anterior cruciate ligament injury induced by internal tibial torsion or tibiofemoral compression. J. Biomech., 41 (16): 3377-83, 2008.

32- AMIS A.A. and DAWKINS G.: Functional anatomy of the anterior cruciate ligament: Fiber bundle actions related to ligament replacements and injuries. J. Bone Joint Surg., 73: 260-7, 1991.

33- GULER O., LSYAR M., KARATAS D., ORMECI T., CERCI H. and MAHIROGULLARI M.: Investigating the relationship between internal tibial torsion and medial collateral ligament injury in patients undergoing knee arthroscopy due to tears in the posterior one third of the medial meniscus. The Knee, 23 (4): 655-8, 2016.

34- TURNER M.S.: The association between tibial torsion and knee joint pathology. Clin. Orthop. Relat. Res., 302: 47-51, 1994.

35- YAGI T.: Tibial torsion in patients with medial type osteoarthrotic knees. Clin. Orthop. Relat. Res., 302: 526, 1994.

36- REIKERAS O.: Patellofemoral characteristics in patients with increased femoral anteversion. Skeletal. Radiol., (21): 311-3, 1992.

37- MONTGOMERY L.C., NELSON F.R. and NORTON J.P.: Orthopedic history and examination in the etiology of overuse injuries. Med. Sci. Sports Exerc., 21: 237-43, 1989.

38- ECKHOFF D.G.: Femoral anteversion in arthritis of the knee. J. Pediat. Orthop., 15: 700, 1995.

39- DANESHMANDI H., SAKI F. and KHOORI A.: Lower extremity malalignment and its linear relation with 
Q-angle in female athletes. Procedia Social and Behavioral Sciences, 15: 3349-54, 2011.

40- ALMEIDA G.P., MAGALHAES M.O. and BURKE T.N.: Q-angle in patellofemoral pain: Relationship with dynamic knee valgus, hip abductor torque, pain and function. Rev. Bras. Ortop., 51 (2): 181-6, 2016.

41- THIJS Y., PATTYN E., VAN TIGGELEN D., ROMBAUT L. and WITVROUW E.: Is hip muscle weakness a predisposing factor for patellofemoral pain in female novice runners? A prospective study. Am. J. Sports Med., 39 (9): 1877-82, 2011

42- RAMSKOV D., JENSEN M.L., OBLING K., NIELSEN R.O., PARNER E.T. and RASMUSSEN S.: No association between Q-angle and foot posture with running-related injuries: A 10 week prospective follow-up study. Int. J. Sports Phys. Ther., 8 (4): 407-15, 2013.

43- BOLING M.C., PADUA D.A. and CREIGHTON R.A.: Concentric and eccentric torque of the hip musculature in individuals with and without patellofemoral pain. J. Athl. Train., 44 (1): 7-13, 2009.

44- LUN V., MEEUWISSE W.H., STERGIOU P. and STEFANYSHYN D.: Relation between running injury and static lower limb alignment in recreational runners. Br. J. Sports Med., (38): 576-80, 2004.

45- EMAMI M.J., GHAHRAMANI M.H., ABDINEJAD F. and NAMAZI H.: Q-angle: An invaluable parameter for evaluation of anterior knee pain. Arch. Iran Med., 10: 24 6, 2007.

46- COWAN D.N., JONES B.H., FRYKMAN P.N., POLLY D.W., HARMAN, E.A., ROSENSTEIN R.M., et al.: Lower limb morphology and risk of overuse injury among male infantry trainees. Med. Sci. Sports Exerc., 28: 945$52,1996$.

47- PARK S.K. and STEFANYSHYN D.J.: Greater Q-angle may not be a risk factor of patellofemoral pain syndrome. J. Clin. Biomech., 26 (4): 392-6, 2010

48- ALIBERTI S., COSTA M.S. and ARNONE A.C.: Clinical rearfoot and knee static alignment measurements are not associated with patellofemoral pain syndrome. Fisioter Pesq., 19 (1): 45-51, 2012

49- LIVINGSTON L.A. and MANDIGO J.L.: Bilateral rearfoot asymmetry and anterior knee pain syndrome. J. Orthop. Sports Phys. Ther., 33: 48-55, 2003.

50- BARTON C.J., BONANNO D., LEVINGER P. and MENZ H.B.: Foot and ankle characteristics in patellofemoral pain syndrome: A case-control and reliability study. J. Orthop. Sports Phys. Ther., 40: 286-96, 2010.

51- MESSIER S.P. and PITTALA K.A.: Etiologic factors associated with selected running injuries. Med. Sci. Sports Exerc., 20: 501-5, 1998.

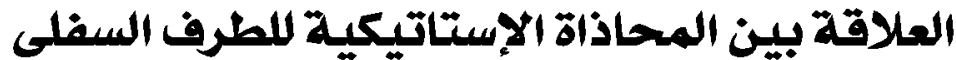

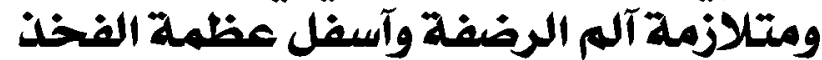

\author{
الغرض من هذه الدراسة التحقق من وجود آية علاقة بين المحاذاة الإستاتيكية للطرف السفلى ومتلازمة آلم الرضفة وآسفل عظمة الفخذ. \\ تم إجراء الدراسة على مدار خمس شهود فى العيادة الخارجية فى القصر العينى. إشتملت هذه الدراسة على تسع وآريعون مريض ومريضة

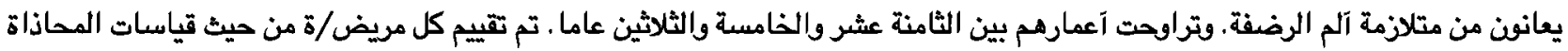

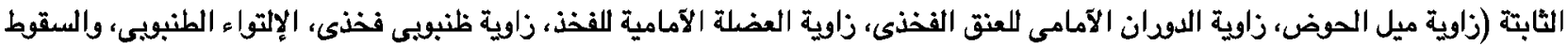

آثبتث نتائج الدراسة عدم وجود علاقة بين زاوية ميل الحوض والوظيفة الحركية وكذلك عدم وجود علاقة بين زاوية الدوران الآمامى للعنق

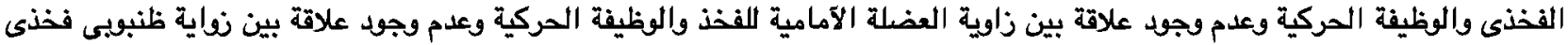
والوظيفة الحركية وكذلك عدم وجود علاقة بين الإلتواء الطنبوبى والوظيفة الحركية وعدم وجود علاقة بين السقوط الزفية الوقى والوظيفة الحركية فى 


\section{Appendix}

\section{Kujala Questionnaire for Patellofemoral Joint Pain}

Name: Date:

Age :

Knee: L/R

Duration of symptoms: Years Months

For each question, circle the latest choice (letter) which corresponds to your knee symptoms.

\section{1- Limp:}
(a) None (5)
(b) Slight or periodical (3)
(c) Constant (0)

\section{2- Support:}
(a) Full support without pain (5)
(b) Painful (3)
(c) Weight bearing impossible (0)

\section{3- Walking:}
(a) Unlimited (5)
(b) More than $2 \mathrm{~km}(3)$
(c) $1-2 \mathrm{~km}(2)$
(d) Unable (0)

4- Stairs:
(a) No diffivulty (10)
(b) Slight pain when descending (8)
(c) Pain both when descending and ascending (5)
(d) Unable (0)

\section{5- Squatting:}
(a) No difficulty (5)
(b) Repeated squatting painful (4)
(c) Painful each time (3)
(d) Possible with partial weight bearing (2)
(e) Unable (0)

\section{6- Running:}
(a) No difficulty (10)
(b) Pain after more than $2 \mathrm{~km}(8)$
(c) Slight pain from start (6)
(d) Severe pain (3)
(e) Unable (0)

\section{7- Jumping:}
(a) No difficulty (10)
(b) Slight difficulty (7)
(c) Constant pain (2)
(d) Unable (0)

8- Prolonged sitting with the kness flexed:
(a) No difficulty (10)
(b) Pain after exercise (8)
(c) Constant pain (6)
(d) Pain forces to extend kness temporarily (4)
(e) Unable (0)

\section{9- Pain:}
(a) None (10)
(b) Slight and occasional (8)
(c) Interferes with sleep (6)
(d) Occasionally severe (3)
(e) Constant and severe (0)

10- Swelling:
(a) None (10)
(b) After severe exertion (8)
(c) After daily activities (6)
(d) Every evening (4)
(e) Constant (0)

11- Abnormal painful kneecap (patellar) movements (subluxations):
(a) None (10)
(b) Occasionally in sports activities (6)
(c) Occasionally in dailyy activities (4)
(d) At least 1 documented dislocation (2)
(e) More than 2 dislocations (0)
(e) More than 2 dislocations (0)

12- Atrophy of thing:
(a) None (5)
(b) Slight (3)
(c) Severe (0)

\section{3- Flexion deficiency:}
(a) None (5)
(b) Slight (3)
(c) Severe (0) 